Article

\title{
Phytol-Loaded Solid Lipid Nanoparticles as a Novel Anticandidal Nanobiotechnological Approach
}

\author{
Tábata L. C. Lima ${ }^{1,+}{ }^{,}$Luanda B. F. C. Souza ${ }^{2,+}$, Lannya C. S. Tavares-Pessoa ${ }^{1}$, \\ Alaine M. dos Santos-Silva ${ }^{1}$ (D), Rômulo S. Cavalcante ${ }^{3}$, Raimundo F. de Araújo-Júnior ${ }^{3}$, \\ Alianda M. Cornélio ${ }^{3}$, Matheus F. Fernandes-Pedrosa ${ }^{1}$, Guilherme Maranhão Chaves ${ }^{2, *}$ and \\ Arnóbio Antônio da Silva-Júnior 1,* \\ 1 Laboratory of Pharmaceutical Technology and Biotechnology, Department of Pharmacy, \\ Federal University of Rio Grande do Norte (UFRN), Gal. Gustavo Cordeiro de Farias, S/N, Petrópolis, \\ Natal-RN 59072-570, Brazil; tabata.cunhalima@gmail.com (T.L.C.L.); claratavares@ufrn.edu.br (L.C.S.T.-P.); \\ alaine.maria@hotmail.com (A.M.d.S.-S.); mffpedrosa@gmail.com (M.F.F.-P.) \\ 2 Department of Clinical and Toxicological Analyses, Federal University of Rio Grande do Norte (UFRN), Gal, \\ Gustavo Cordeiro de Faria, S/N, Petrópolis, Natal-RN 59084-100, Brazil; luandacanario@ufrn.edu.br \\ 3 Department of Morphology, Federal University of Rio Grande do Norte (UFRN), Natal-RN 59.078-970, Brazil; \\ romulo.s.cavalcante@gmail.com (R.S.C.); araujojr.morfologia@gmail.com (R.F.d.A.-J.); \\ aliandamaira@gmail.com (A.M.C.) \\ * Correspondence: guilherme.chaves@ufrnet.br (G.M.C.); arnobiosilva@pq.cnpq.br (A.A.d.S.-J.); \\ Tel.: +55-084-3342-9820 (A.A.d.S.-J.); Fax: +55-084-3342-9833 (A.A.d.S.-J.) \\ + These authors contribute equally to this paper.
}

Received: 16 July 2020; Accepted: 28 August 2020; Published: 13 September 2020

\begin{abstract}
Phytol is a diterpene alcohol and can be found as a product of the metabolism of chlorophyll in plants. This compound has been explored as a potential antimicrobial agent, but it is insoluble in water. In this study, we describe a novel approach for an interesting anticandidal drug delivery system containing phytol. Different formulations of phytol-loaded solid lipid nanoparticles (SLN) were designed and tested using a natural lipid, 1,3-distearyl-2-oleyl-glycerol (TG1). Different compositions were considered to obtain three formulations with 1:10, 1:5, and 1:3 w/w phytol/TG1 ratios. All the formulations were prepared by emulsification solvent evaporation method and had their physicochemical properties assessed. The biocompatibility assay was performed in the HEK-293 cell line and the antifungal efficacy was demonstrated in different strains of Candida ssp., including different clinical isolates. Spherical and uniform SLN (<300 nm, PdI < 0.2) with phytol-loading efficiency $>65 \%$ were achieved. Phytol-loaded SLN showed a dose-dependent cytotoxic effect in the HEK-293 cell line. The three tested formulations of phytol-loaded SLN considerably enhanced the minimal inhibitory concentration of phytol against 15 strains of Candida spp. Considering the clinical isolates, the formulations containing the highest phytol/TG1 ratios showed MICs at $100 \%$. Thus, the feasibility and potential of phytol-loaded SLN was demonstrated in vitro, being a promising nanocarrier for phytol delivery from an anticandidal approach.
\end{abstract}

Keywords: solid lipid nanoparticles; phytol; Candida spp.; 1,3-distearyl-2-oleyl-glycerol (TG1); anticandidal activity

\section{Introduction}

In the last few decades it is estimated that more than 150 million individuals develop severe fungal diseases every year, resulting in high rates of morbidity and mortality [1]. Yeasts belonging to the Candida genus are outstanding among opportunistic fungi. Candida species belong to the normal human microbiota and typically grow on the skin and mucosal surfaces such as the gastrointestinal 
genitourinary and respiratory tract [2,3]. Nevertheless, under favorable conditions, this opportunistic microorganism can rapidly change from commensal to pathogenic condition, causing a diverse spectrum of clinical diseases ranging from superficial and mucosal infections to invasive diseases associated with candidemia and metastatic organ involvement [4-6].

Vulvovaginal candidiasis (VVC) is a long-term condition that can severely affect the quality of life of affected women and is associated with considerable stress. VVC has been considered a global public health problem, affecting millions of women of all social strata. It causes great discomfort, impairs sexual relationships, and damages work performance [7]. Invasive infections due to Candida spp. are widely recognized as a major cause of morbidity and mortality in the healthcare environment and it is estimated that over 750,000 cases of invasive candidiasis are reported per year. [1,8]. In addition, approximately $40 \%$ of attributable mortality is found for patients with invasive candidiasis, despite therapy with conventional antifungal drugs $[9,10]$. At least 15 distinct Candida species may cause human diseases, whereas more than $95 \%$ of invasive infections are caused by the 5 most common Candida spp.: Candida albicans, Candida glabrata, Candida tropicalis, Candida parapsilosis, and Candida krusei [11].

For the treatment of different clinical forms of candidiasis, four major classes of antifungal agents have been widely used: the polyenes (i.e., amphotericin B and nystatin), the azoles (i.e., fluconazole, itraconazole, and voriconazole), the echinocandins (i.e., caspofungin, micafungin, and anidulafugin), and 5-flucytosine. However, the recent emergence of multidrug-resistant Candida species, such as Candida auris, has led to limitations to choose the appropriate antifungal therapy [12,13], which highlights the need for the discovery of new targets to treat both superficial and invasive candidiasis. In this context, plants and their natural compounds are excellent options to obtain a wide variety of drugs [14]. In this sense, it is possible to find reports in the literature showing that recently the antimicrobial activity of natural products has been widely researched and suggested as a possible therapeutic alternative [15-17].

Among natural products, essential oils have attracted attention because they are secondary metabolites that represent a very complex natural mixture with several components present in significantly different concentrations found in plants [18]. Diterpenes are a class of compounds commonly found in essential oils. These compounds are increasingly catching the attention due to their important biological activities [18-20]. Phytol(3,7,11,15-tetramethylhexadec-2-EN-1-OL), a branched long chain unsaturated diterpene member found abundantly in nature, is a product of the metabolism of chlorophyll in plants [21,22]. In the literature it was found that phytol exhibits a wide range of bioactivities including antioxidant [23,24], apoptosis-inducing and anti-angiogenic [25], and antimicrobial/antifungal activities [22,26]. Despite this good biological activity, phytol presents limitations as its solubility in aqueous solution, such as biological fluids, due to being a highly hydrophobic compound [27]. These characteristics lead to low bioavailability of this molecule. However, this problem can to be overcome with applications of effective drug delivery systems (DDSs) such as biocompatible/biodegradable nanocarriers [28].

In the literature, there are few studies that evaluate the advantages of drug delivery systems containing phytol. In previous studies, Sathya et al. (2020) [29-31] evaluated the activity of phytol-loaded poly (lactic-co-glycolic acid) nanoparticles as a possible treatment for Alzheimer's disease. In addition, studies conducted by Islam et al. (2017) evaluated the antioxidant, toxicity, and cytotoxic effect of phytol-loaded nanoemulsions [24,32]. These studies suggests that phytol induces apoptosis dur to perturb the ionic balance, triggering changes in the membrane potential. The reported necrosis was associated with the augmented production of reactive oxygen cell species (ROSs). Studies performed by Sakthivel, Malar, and Devi corroborated with the apoptotic activity of phytol in A549 cells by a similar mechanism to that described above [25]. Nevertheless, the mechanism by which terpenes work as antimicrobial agent against bacteria and fungi has not yet been fully described. However, advanced studies suggest that it can act by inactivating enzymes and proteins important for the metabolism of microorganisms, as well as contributing to cell membrane damage due to intracellular potassium ion loss [33,34]. Thus, we hypothesized that this biological activity can 
be efficiently applied as a promising anticandidal agent, and its encapsulation in nanocarriers can improve this activity.

To date, no study has reported the evaluation drug delivery systems containing phytol as antimicrobial agents. Therefore, this fact makes this study a pioneer when it comes to the performance of phytol incorporated in nanocarriers, especially in the case of anticandidal activity.

Nanocarriers can be formulated using organic materials, playing a role as an important strategy for protecting active pharmaceutical ingredients. In addition, they change some properties of these drugs, such as the solubility, stability pharmacokinetics, biodistribution, and toxicity. Furthermore, the controlled drug release and site-specific drug delivery maximizes the clinical benefits while limiting their side effects [33-35]. In this background, solid lipid nanoparticles (SLN) are colloidal systems that have been explored to different purposes. On the contrary to nanoemulsions, SLN can be incorporated in ointments and creams as the final galenic dosage forms preserving the nanostructure. The dispersion of polymeric nanoparticles in these pharmaceutical dosage forms can also be a limitation.

The many advantages of SLN include good biocompatibility and low toxicity due to the lipid-like composition, as well as the sustained release for lipophilic drugs in an aqueous environment [36,37]. However, interaction of nanocarriers with cell membranes is a determinant factor for their cellular uptake, which could depend on nanoparticles size, shape, charge, and their surface characteristics [38]. In this context, it is important to evaluate the interactions of nanocarrier with targeted cells for improving the drug uptake. In this study, phytol was incorporated in SLN using different lipid/phytol ratios as a tentative to achieve a novel and promising nanobiotechnological approach with improved anticandidal activity, mainly considering the classical drugs.

\section{Materials and Methods}

\subsection{Materials}

The 1,3-distearyl-2-oleyl-glycerol (TG1) was donated by the Federal University of Piauí (Teresina, Brazil). The use of plant material was conducted under authorization from the National System for Management of Genetic Heritage and Associated Traditional Knowledge (SISGEN) no. ACB9C9D. Phytol diterpene was supplied by Sigma-Aldrich (São Paulo, Brazil). The polyvinyl alcohol (PVA), having a viscosity molecular mass of $4.7 \times 10^{4} \mathrm{~g} / \mathrm{mol}$, was obtained from Vetec (São Paulo, Brazil). Dimethylsulfoxide (DMSO) and Alamar blue were purchased from Sigma-Aldrich (São Paulo, Brazil). The purified water $(1.3 \mu \mathrm{S})$ was prepared from a reverse osmosis purification equipment model OS50 LX (Gehaka, São Paulo, Brazil). All other chemicals and reagents were of analytical grade.

\subsection{Preparation of Nanoparticles}

Solid lipid nanoparticles (SLN) were prepared by the emulsification solvent evaporation method [35]. For this, 1,3-distearyl-2-oleyl glycerol (TG1) was used as a lipid matrix. Briefly, the organic phase (OP) $(6 \mathrm{~mL})$ that was composed of dichloromethane (DCM) containing TG1 $(0.5 \% w / v)$ and phytol $(0.05 \% w / v, 0.1 \% w / v$, and at $0.16 \% w / v)$ to obtain a TG1/PHY ratio of $1: 10,1: 5$, and 1:3 w/w, respectively. This organic phase was injected into the aqueous phase (AP) that was composed of $14 \mathrm{~mL}$ of the purified water containing the surfactant PVA $(0.5 \% w / v)$ under magnetic stirring at $720 \mathrm{rpm}$ at $25^{\circ} \mathrm{C} \pm 2{ }^{\circ} \mathrm{C}$. The two OP and AP were previously filtered using $0.45 \mu \mathrm{m}$ membranes (Sartorius, Goettingen, Germany). The emulsification was followed in Ultra-turrax equipment (IKA-Labortechnik, Staufen im Breisgau, Germany) at 20,000 rpm for $18 \mathrm{~min}$ and evaporation of the solvent occurred at $25{ }^{\circ} \mathrm{C}$ under magnetic stirring at $720 \mathrm{rpm}$ overnight. Under same conditions, blank-solid lipid nanoparticles (SLN-B), without phytol, were prepared. The final colloidal dispersions were placed in hermetically sealed glass flasks and stored at $25^{\circ} \mathrm{C} \pm 2{ }^{\circ} \mathrm{C}$. All experiments were performed in triplicate, and the data were expressed as mean \pm standard deviation (SD). 


\subsection{Physicochemical Properties and Stability}

\subsubsection{Particle Size and Zeta Potential Measurements}

Mean particle size and polydispersity index (PdI) were assessed by using dynamic light scattering (DLS) in a particle size analyzer ZetaSize NanoZS (Malvern Instruments, Malvern, UK) at $659 \mathrm{~nm}$ wavelength, $173^{\circ}$ detection angle, and at $25^{\circ} \mathrm{C}$. Zeta potential ( $\zeta$ potential) measurements were performed in the same equipment through applying a field strength of about $5.9 \mathrm{~V} \cdot \mathrm{cm}^{-1}$ by using the electrophoretic mobility. The measurements were performed for at least 10 determinations for each sample diluted at 1:50 (v/v) with purified water. All experiments were performed in triplicate and data were expressed as mean \pm standard deviation (SD).

\subsubsection{Attenuated Total Reflectance Fourier Transform Infrared (ATR-FTIR) Spectroscopy}

The interactions of phytol with SLN were assessed using attenuated total reflectance Fourier transform infrared (ATR-FTIR) spectroscopy. The colloidal dispersions were lyophilized in a freeze-dryer (LIOTOP_L202) for $48 \mathrm{~h}$. The spectra were recorded at 20 scans, with a resolution of $4 \mathrm{~cm}^{-1}$ between 4000 and $500 \mathrm{~cm}^{-1}$ for pure compounds (Phytol, PVA, TG1), SLN-B, and phytol-loaded SLN using three TG1/PHYTOL ratios (1:10, 1:5, and 1:3 w/w) using a FTIR-ATR spectrophotometer, SHIMADZU IR Prestige 21 (Tokyo, Japan).

\subsubsection{Physicochemical Stability}

The colloidal dispersions of SLN were stored in the hermetically closed flasks at $25^{\circ} \mathrm{C}$ for 6 weeks. At the intervals of 7 days, the samples were collected and had their size and zeta potential determined. The measurements were performed at $25^{\circ} \mathrm{C}$ using the parameters described in Section 2.3.1. All analyses were performed in triplicate, and the data were expressed as mean \pm standard deviation (SD).

\subsubsection{Atomic Force Microscopy (AFM) and Scanning Electron Microscopy (SEM)}

The shape and surface of SLN-B and phytol-loaded solid lipid nanoparticles were observed by using AFM and SEM images. The dispersions were freshly diluted in purified water with a ratio of 1:25 (v/v) and dropped in a cover slip, dried under a desiccator with duration of $24 \mathrm{~h}$, and then analyzed in an AFM and after in an SEM. The AFM analyses were performed using aSPM-9700 from Shimadzu (Tokyo, Japan) coupled with a cantilever non-contact, $1 \mathrm{~Hz}$ scanning. For the SEM images, one drop of each nanoparticle dispersion was placed on a washed microscope carbon slide and dried under a desiccator for $24 \mathrm{~h}$ and then in a field emission gun scanning electron microscope (FEG-SEM; Carl Zeiss, Auriga, East Lansing, MI, USA).

\subsection{Drug-Loading Efficiency}

Samples were centrifuged at $16,000 \times g$ for $60 \mathrm{~min}$ at $4{ }^{\circ} \mathrm{C}$ using the centrifugal filter (Merck Millipore, Darmstadt, Germany, Microcon, -10 kDa with Ultracel-10 membrane). After centrifugation, the filtered solution was analyzed to determine drug concentration using the UV-VIS spectrophotometry (Thermo Fisher Scientific, 60S Evolution, Madison, WI, USA) method at $239 \mathrm{~nm}$, utilizing the equation from the fitted standard curve plot constructed previously [24]. The encapsulation efficiency (EE) was calculated by using Equation (1), where the total drug amount added (Drug total $_{\text {) }}$ and the non-entrapped drug

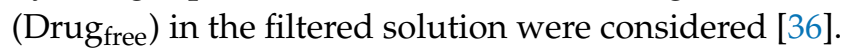

$$
\mathrm{EE}(\%)=\frac{[\text { Drug }] \text { total }-[\text { Drug }] \text { free }}{[\text { Drug }] \text { total }} \times 100
$$




\subsection{Antifungal Activity}

\subsubsection{Candida spp. Strains and Clinical Isolates}

The following Candida reference strains obtained from the American Type Culture Collection (ATCC) and Centraalbureau voor Schimmelcultures (CBS) were used: Candida albicans ATCC 90028, Candida dubliniensis CBS 7987, Candida tropicalis ATCC 13803, Candida parapsilosis ATCC 22019, Candida glabrata ATCC 2001, Candida rugosa ATCC 10571, and Candida krusei ATCC 6258. Clinical isolates obtained from patients with vulvovaginal candidiasis (LMMM 92 and LMMM 100) or candidemia (LMMM 83, LMMM 85, LMMM 195, LMMM 249, LMMM 447, LMMM 704) used during this study belongs to the culture collection of the Medical and Molecular Mycology Laboratory, Clinical and Toxicological Analyses Department, at the Federal University of Rio Grande do Norte. This study was approved by the Local Research Ethics Committee ("Comitê de Ética em Pesquisa da Liga Norte Riograndense Contra o Câncer") under the protocol number 042/042/2012. The strains were stored at $-80{ }^{\circ} \mathrm{C}$ in yeast extract peptone dextrose (YPD) broth $\left(10 \mathrm{~g} \cdot \mathrm{L}^{-1}\right.$ yeast extract, $20 \mathrm{~g} \cdot \mathrm{L}^{-1}$ glucose, and $20 \mathrm{~g} \cdot \mathrm{L}^{-1}$ mycological peptone) containing $20 \%(v / v)$ glycerol and incubated in a rotator shaker (TE-420, Tecnal Piracicaba, Brazil) at $35^{\circ} \mathrm{C}, 200 \mathrm{rpm}$, for $48 \mathrm{~h}$ for reactivation and verification of cell viability. Subsequently, $100 \mu \mathrm{L}$ of cell suspensions was inoculated on the surface of Sabouraud Dextrose Agar (SDA; Oxoid, Basingstoke, Hampshire, UK) using a Drigalsky loop, and incubated for $48 \mathrm{~h}$ at $35^{\circ} \mathrm{C}$ previously to antifungal susceptibility testing experimentation [38].

\subsubsection{Fungal Minimal Inhibitory Concentration (MIC) Determination of Phytol and Nanoparticles}

For this study, seven different references and eight clinical strains of Candida spp. were tested. The antifungal susceptibility testing was assessed according to the Clinical and Laboratory Standard Institute (CLSI) protocol M27-A2 [39] (Wayne, PA, USA) with adaptations for natural products. For Minimal Inhibitory Concentration assay (MIC), the inoculum of all strains tested was obtained from $48 \mathrm{~h}$ cultivation on SDA at $35^{\circ} \mathrm{C}$ and subsequently an initial suspension was prepared according to the McFarland scale 0.5 standard ( 1 to $5 \times 10^{6}$ cells) by absorbance measurement using a UV-VIS spectrophotometer (Biochrom, Libra S32, Cambourne, UK). Then, two serial dilutions were made, firstly in saline solution (1:50) and then in Mueller-Hinton growth medium (HiMedia, Mumbai, India) (1:20). Subsequently, $100 \mu \mathrm{L}$ aliquots of the final inoculum solution of each species were dispensed in different microtiter plates of 96 wells. Posteriorly, the strains were incubated, independently, with $100 \mu \mathrm{L}$ of phytol (10,000-19.53 $\mu \mathrm{g} / \mathrm{mL})$, SLN-B (173.5-0.33 $\mu \mathrm{g} / \mathrm{mL}), 10-S L N-P H Y ~(62.5-0.12 \mu \mathrm{g} / \mathrm{mL}), 5-S L N-P H Y$ $(125-0.24 \mu \mathrm{g} / \mathrm{mL})$, and 3-SLN-PHY $(208.33-0.40 \mu \mathrm{g} / \mathrm{mL})$. The samples were diluted in Mueller-Hinton growth medium. As a control for antifungal activity, fluconazole was used with concentrations ranging from 64 to $0.125 \mu \mathrm{g} / \mathrm{mL}$. Finally, the plates were incubated at $37^{\circ} \mathrm{C}$ and a test reading was taken after $48 \mathrm{~h}$ incubation. The MIC was considered the lowest concentration of the phytol and nanoparticles capable of inhibiting $50 \%$ or $100 \%$ of the growth of each strain, taking as reference the respective positive control (treated in the same manner, but without the treatment added to yeast cells).

\subsection{Cell Viability Experiments}

\subsubsection{Cell Culture}

The human embryonic kidney epithelial cells lines (HEK-239) were maintained according to the specifications of the Cell Bank of Rio de Janeiro, Brazil. Briefly, the cells were maintained at $37^{\circ} \mathrm{C}$ and $5 \% \mathrm{CO}_{2}$ and cultured with DMEM (Dulbecco's modified Eagle's medium) culture medium supplemented with $10 \%$ of fetal bovine serum and $0.15 \%$ penicillin/streptomycin $(10,000 \mathrm{U} / \mathrm{mL})$ in $75 \mathrm{~cm}^{2}$ culture bottles. 


\subsubsection{In Vitro Cell Viability Assay}

The cell viability assay was determined by the resazurin reduction method, which evaluates cell viability by the enzymatic activity of mitochondrial dehydrogenases. For this, HEK-239 cells were grown in 96-well plates at a density of $4 \times 10^{3}$ cells per well for $24 \mathrm{~h}$ until complete adhesion. After this period, cells were incubated for 24 and $48 \mathrm{~h}$ in the presence of different serial dilutions of samples. The SLN-B $(0 ; 5.4 ; 10.8 ; 21.6 ; 43.3 ; 86.7 ; 173.5 ; 374.0 \mu \mathrm{g} / \mathrm{mL})$, the 5-SLN-PHY $(0 ; 1.9 ; 3.9 ; 7.8 ; 15.6 ; 31.2$; $62.5 ; 125 \mu \mathrm{g} / \mathrm{mL})$, and the $3-S L N-P H Y(0 ; 3.2 ; 6.5 ; 13 ; 26 ; 52 ; 104 ; 208.3 \mu \mathrm{g} / \mathrm{mL})$ were tested. The samples were diluted in culture medium without fetal bovine serum. For phytol, a stock solution of $5 \mathrm{mg} / \mathrm{mL}$ containing $2 \%$ DMSO was prepared and then was diluted $(0 ; 3.9 ; 7.8 ; 15.6 ; 31.2 ; 62.5 ; 125 ; 250 \mu \mathrm{g} / \mathrm{mL})$ in culture medium without fetal bovine serum. After the treatment time, $10 \mu \mathrm{L}$ of resazurin solution $(0.04 \%)$ was added to each well and the plate was incubated again for $4 \mathrm{~h}$. Posteriorly, the absorbance was then measured on a microplate reader (Epoch, BioTek, Winooski, VT, USA) at wavelengths of 570 and $600 \mathrm{~nm}$. The cell viability was calculated using the equation below (Equation (2)).

$$
\text { Reduction of resazurin }(\%)=\frac{\mathrm{A} 570-(\mathrm{A} 600 \times \mathrm{FC})}{\mathrm{Ac570}-(\mathrm{Ac} 600 \times \mathrm{FC})} \times 100
$$

where A570 is the absorbance determined at $570 \mathrm{~nm}$ for samples, A600 is the absorbance determined at $600 \mathrm{~nm}$ for samples, Ac570 is the absorbance determined at $570 \mathrm{~nm}$ of the untreated group, Ac600 is the absorbance determined at $600 \mathrm{~nm}$ for the untreated group. The FC is the used correction factor.

For the determination of the cytotoxic concentration $\left(\mathrm{CC}_{50}\right)$ values, we used nonlinear regression of concentration-response curves. The $\mathrm{CC}_{50}$ was defined as the concentration that reduced cell viability by $50 \%$ when compared to untreated controls [36]. All measurements were carried out in triplicate with three replicates for each dilution.

\subsection{Statistical}

All experimental values were expressed as mean \pm standard deviation (SD). The pairwise comparisons of the analytical data were performed using the Student's $t$-test. One-way analysis of variance (ANOVA) was applied for multiple comparisons, followed by the post hoc test of Dunnett's vs. a control group. Data from cell viability assay were compared using one-way analysis of variance followed by Bonferroni's test. A value of $p<0.05$ was considered to be statistically significant.

\section{Results and Discussion}

\subsection{Preparation of Drug-Loaded Solid Lipid Nanoparticles}

SLN were successfully prepared using the selected parameters. Slightly turbid and opaque colloidal dispersions were observed $24 \mathrm{~h}$ after the preparation. Any phase separation was observed. The experimental design initially included the free-drug formulation (SLN-B) and three different phytol-loaded SLN using drug/TG1 ratios of 1:10 $w / w$ (10-SLN-PHY), 1:5 w/w (5-SLN-PHY), and 1:3 w/w (3-SLN-PHY). All the formulations were prepared using the same experimental conditions. Table 1 shows the physicochemical properties of different formulations of SLN. The increasing amount of phytol in the SLN did not affect their mean diameter of approximately $300 \mathrm{~nm}$, their particle size distribution ( $\mathrm{PdI}<0.2)$, or their negative zeta potential. In addition, high drug-loading efficiency was achieved for three formulations. 
Table 1. Physicochemical properties of different solid lipid nanoparticles (SLN) formulations.

\begin{tabular}{ccccccc}
\hline Nanoparticles & TG1/Phytol Ratio & pH & Size (nm) & PdI & ZP (mV) & EE (\%) \\
\hline SLN-B & - & 6.8 & $297.6 \pm 28.5$ & $0.15 \pm 0.03$ & $-16.0 \pm 2.2$ & - \\
10-SLN-PHY & $1: 10$ & 6.4 & $307.4 \pm 12.5$ & $0.15 \pm 0.07$ & $-16.3 \pm 11.1$ & 67.38 \\
5-SLN-PHY & $1: 5$ & 6.5 & $302.2 \pm 10.0$ & $0.12 \pm 0.03$ & $-16.7 \pm 0.5$ & 68.74 \\
3-SLN-PHY & $1: 3$ & 6.5 & $297.9 \pm 2.4$ & $0.14 \pm 0.02$ & $-18.6 \pm 1.0$ & 68.20 \\
\hline
\end{tabular}

Note: Data are expressed as mean \pm standard deviation $(n=3)$. TG1, 1,3-distearoyl-2-oleoylglycerol; PdI, polydispersity index; $\mathrm{ZP}$, zeta potential; $\mathrm{EE} \%$, encapsulation efficiency.

The preparation of monodisperse colloidal systems $(\mathrm{PDI}<0.2)$ is important to predict their behavior and interaction with biological surfaces, mainly the capacity to overcome biological membranes [40,41]. Generally, the size of SLN ranges from 100 to $400 \mathrm{~nm}$, yet negative zeta potential values between -20 and $-40 \mathrm{mV}$ were observed due to the nature of lipids used [42,43]. As already mentioned, phytol is a poorly water-soluble molecule. Anterior studies have reported encapsulation efficiency about of $90 \%$ for phytol in the PLGA nanoparticles [29-31]. This is an important parameter for characterizing SLN. Several factors such as the type and concentration of the lipid, as well as the used surfactant can affect this parameter for SLN. Certainly, changing these formulation parameters or nanoencapsulation method could enhance the entrapment of phytol in the SLN. However, the TG1 was chosen as the main and only structural lipid material due to be extracted from butter of Platonia insignis, a natural species that is part of the Brazilian biodiversity. PVA was used as surfactant due to its more predictable biocompatible formulations. The prepared SLN allowed its efficient dispersion in aqueous colloidal dispersions, with drug encapsulation efficiency being higher than $65 \%$ in the lipid matrix (Table 1 ). This was an important achievement, mainly considering the encapsulation efficiency of diterpenes in SLN [44-46]. Moreover, the SLN formulations containing phytol showed slightly lower $\mathrm{pH}$, but no statistical difference was identified when compared to free-drug formulation. The physicochemical stability and morphology of SLN were also considered in this approach.

\subsection{Morphology and Physicochemical Stability}

Both AFM and SEM images have shown morphological and topographic aspects, such as shape and surface of SLN formulations. Different images of the formulation SLN-B (Figure 1a), 5-SLN-PHY (Figure 1b), and 3-SLN-PHY (Figure 1c) can be compared. The 2D and 3D AFM images can be seen at the left and center, while the SEM images can be observed at right of the pictures. Uniform and spherical solid lipid nanoparticles can be observed, with slightly smooth surfaces. This achievement corroborates with particle size experiments. In addition, the ability of different formulations for preserving the colloidal aspect and particle size was assessed for 6 weeks (Figure 2).

\subsection{Mean Diameter and Zeta Potential as a Function of Storage Time for Different Formulations of SLN}

The mean diameter, polydispersity index, and zeta potential were evaluated. The freshly produced samples were stored at room temperature $\left(25^{\circ} \mathrm{C}\right)$ and the first measurement was performed after $24 \mathrm{~h}$, being repeated for every 7-day interval. This study was performed to assess the effect of drug loading on the physical stability of SLN. Different TG1/phytol ratios also were used. All the formulations remained stable, without significant changes in size and zeta potential. The phytol-loading at three different concentrations did not affect the physicochemical stability of SLN formulations. The same was observed for SLN-B (Figure 2). There were no significant variations between particle size and zeta potential values over the 6 weeks for SLN, being an indicative of absence of instability phenomena. 

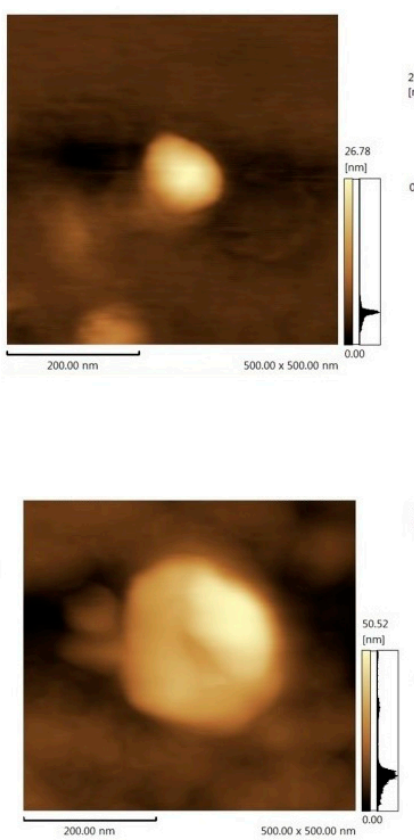

$500.00 \times 500.00 \mathrm{~nm}$

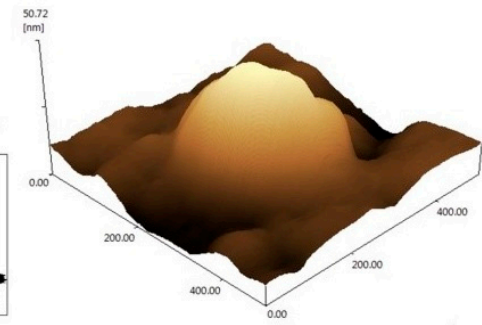

(b)
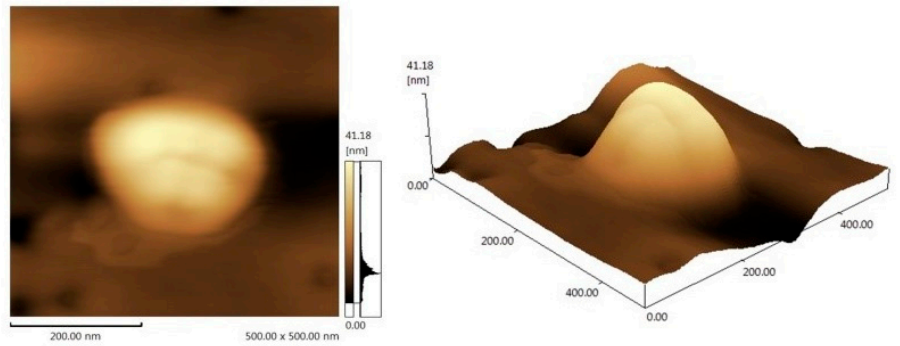

(c)

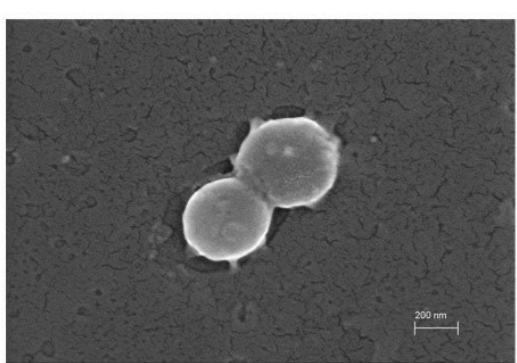

(a)

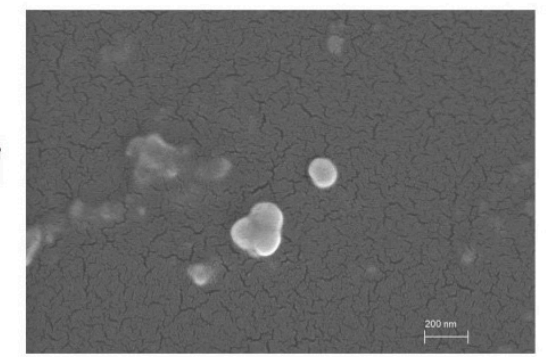

Figure 1. Morphology analyses of 2D and 3D atomic force microscopy (AFM) images and SEM images, respectively, of (a) blank-solid lipid nanoparticles (SLN-B), and phytol-loaded solid lipid nanoparticles (SLN-PHY) (b) 5-SLN-PHY and (c) 3-SLN-PHY.

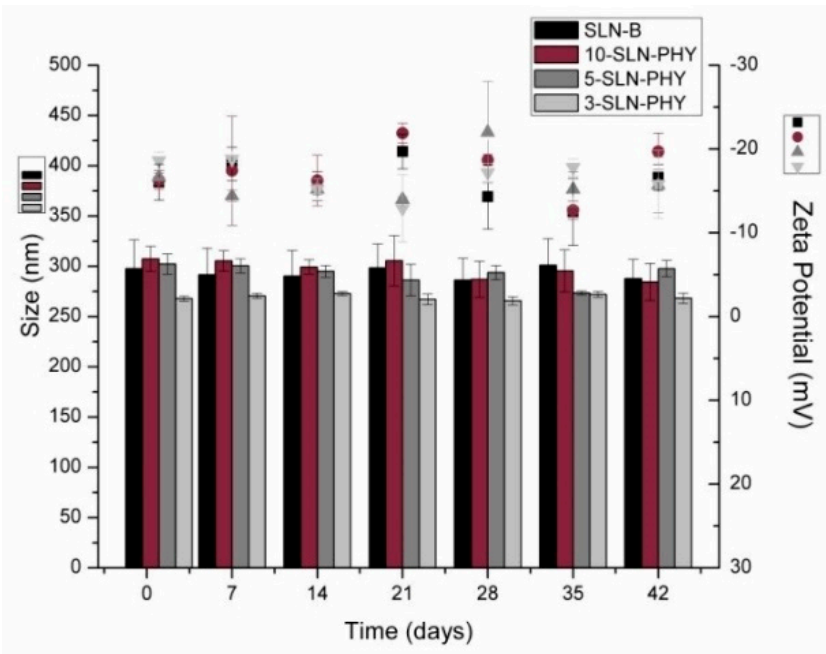

Figure 2. Mean diameter and zeta potential as a function of storage time for the solid lipid nanoparticles (SLN) and phytol-loaded solid lipid nanoparticles (SLN-PHY). Note: The data are expressed as mean \pm standard deviation $(\mathrm{SD})(n=3)$. 


\subsection{Attenuated Total Reflectance Fourier Transform Infrared (ATR-FTIR) Spectroscopy}

The FTIR spectra recorded for TG1, PVA, and blank-solid lipid nanoparticles (SLN-B) are shown in Figure 3a. In the TG1 spectrum, it is possible to observe aliphatic C-H stretch of sp3 and sp2 carbons at $1926 \mathrm{~cm}^{-1}$ and $2850 \mathrm{~cm}^{-1}$, respectively. The bands recorded at $1750 \mathrm{~cm}^{-1}$ and $1468 \mathrm{~cm}^{-1}$ are assigned to $\mathrm{C}=\mathrm{O}$ of ester and angular deformation of $\mathrm{CH}_{2}$. The $\mathrm{C}-\mathrm{O}$ ester stretch and $\mathrm{C}-\mathrm{O}$ of primary alcohol were recorded at $1247 \mathrm{~cm}^{-1}$ and $1048 \mathrm{~cm}^{-1}$, respectively. In the FTIR spectrum of SLN-B, the O-H recorded at $3250 \mathrm{~cm}^{-1}$ and bathochromic of $C=O$ ester band to $1717 \mathrm{~cm}^{-1}$ occurred due to PVA covering on the surface of TG1 nanoparticles. Figure 3b shows FTIR spectra of pure phytol, SLN-B, and three formulations of drug-loaded SLN. The asymmetrical and symmetrical bending vibrations of $\mathrm{C}-\mathrm{H}$ were recorded at $1468 \mathrm{~cm}^{-1}$ and $1372 \mathrm{~cm}^{-1}$, respectively, in the phytol spectrum. The $\mathrm{C}-\mathrm{O}$ of primary alcohol was recorded at $1007 \mathrm{~cm}^{-1}$. Comparisons of three drug-loaded formulations suggested an augmented intensity of bands recorded at $1468 \mathrm{~cm}^{-1}$ and $1372 \mathrm{~cm}^{-1}$ and the bathochromic shift to lower wavenumber range, according the drug/TG1 ration enhanced in the SLN. The primary alcohol band of drug appeared to be overlapped in the nanoparticles.

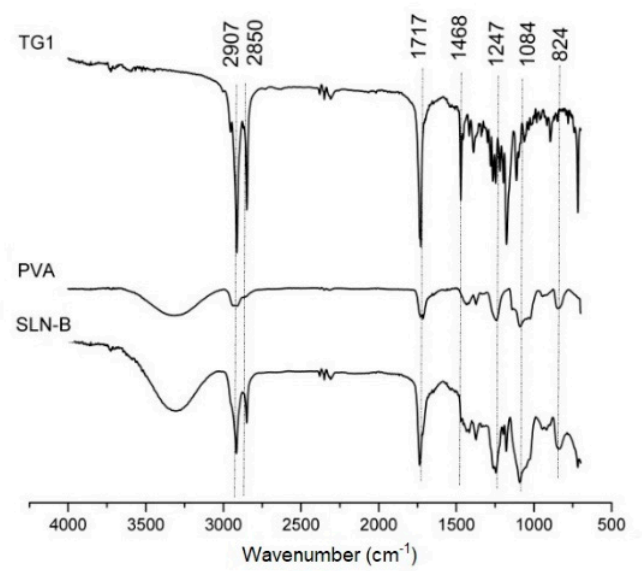

(a)

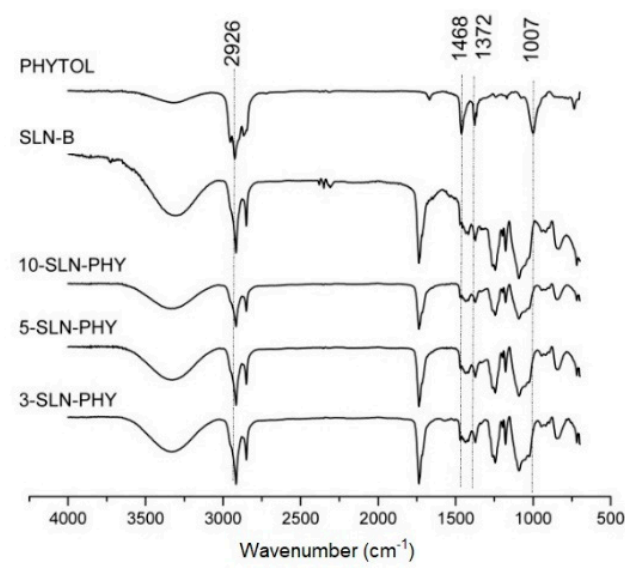

(b)

Figure 3. Attenuated total reflectance Fourier transform infrared (ATR-FTIR) spectra for compounds and different formulations of SLN. (a) Spectra for TG1, PVA, and blank-solid lipid nanoparticles (SLN-B); (b) spectra for phytol, SLN-B, and phytol-loaded nanoparticles (SLN-PHY).

FTIR spectra was applied as an important tool to characterize SLN. The suggested shifts identified in the FTIR spectra of SLN-B and drug-loaded SLN are common in self-assembled nanoparticles, in which their interactions determines their deposition in the particles $[47,48]$. The observed differences in the FIR spectra corroborates with drug-loading experiments. The shifts in spectra of formulations can be associated with drug-loading in the SLN. This achievement is so important to explain possible differences among the biological activity of different samples [31,49]. In this context, the experimental data support the expected ability of SLN for loading of poorly soluble diterpene drugs in an aqueous environment, which can be explored as a potential topical drug delivery system [50].

The use of TG1 as lipid matrix in the SLN formulations is due to this compound being extracted from butter of Platonia insignis, a natural species from Brazil. In studies performed by Feitosa et al. (2015) [51], biochemical and hematological parameters were evaluated, as well as histopathological analysis in brain areas of adult rats treated orally with the TG1 triglyceride. The authors concluded that treatment with TG1 did not produce hematological, biochemical, or histopathological alterations in rats, suggesting low toxicity. In addition to in vitro studies, in vivo studies have been carried out to prove that this compound is biocompatible. This fact is particularly important, mainly considering the mucosal environment affected by candidiasis and candidemia, in which an unprovable homogeneous dispersion of phytol drug is expected. 


\subsection{Anticandidal Assays}

3.5.1. Minimal Inhibitory Concentration (MIC) of Growth in Reference Strains of Candida spp.

In this approach, the anticandidal experiments assessed the MICs and minimum fungicidal concentration (MFC) with the established broth microdilution assay [38]. Thus, it is interesting to report that all MIC values reported in this section corresponded to the lowest dilutions tested for each sample. For this, the maximum concentration of free phytol (PHY) tested was 10,000 $\mu \mathrm{g} / \mathrm{mL}$ $(10 \mathrm{mg} / \mathrm{mL})$, whereas the phytol concentration in the nanoparticles varied according to the drug proportion in the SLN formulations, reaching concentrations 40 -fold lower than those for free phytol. Despite three drug-loaded SLN formulations having similar EE\%, these three samples had different drug rates. We realize that the TG1/phytol ratio is an important variable that affects SLN efficacy as an antimicrobial agent.

At the concentrations tested, SLN-B was not able to inhibit fungal growth. Conversely, results from experiments using PHY and 10-SLN-PHY showed that both treatments were able to inhibit 50\% of fungal growth for all the strains tested. The PHY presented MICs ranging from 2500 to $625 \mu \mathrm{g} / \mathrm{mL}$, whereas the 10-SLN-PHY showed a more remarkable inhibitory activity, where MICs ranged from 15.62 to $1.95 \mu \mathrm{g} / \mathrm{mL}$. For C. albicans ATCC 90028, C. dubliniensis CBS 7987, C. parapsilosis ATCC 22019, and C. glabrata ATCC 2001, the nanoparticles were able to improve the phytol antifungal activity by decreasing MICs of approximately 300 times. PHY and 10-SLN-PHY comparisons allow us to realize that C. glabrata ATCC 2001 was the most susceptible strain, with a 50\% inhibition of visual growth at concentrations of 625 and $1.95 \mu \mathrm{g} / \mathrm{mL}$ for PHY and 10-SLN-PHY, respectively. The C. krusei ATCC 6258 showed the highest $50 \%$ growth MICs, with concentrations of 2500 and $15.62 \mu \mathrm{g} / \mathrm{mL}$ for PHY and 10-SLN-PHY, respectively. When we analyzed the results for the other strains, we verified that the SLN was able to lower the MIC obtained for PHY (10-SLN-PHY). This was observed for C. albicans ATCC 90028 and C. dubliniensis CBS 7987 (Table 2).

Table 2. Minimum inhibitory concentration values of phytol and SLN against Candida spp. reference strains determined with the broth microdilution assay.

\begin{tabular}{|c|c|c|c|c|c|c|}
\hline \multirow{3}{*}{$\begin{array}{c}\text { Candida spp. } \\
\text { Reference Strains }\end{array}$} & \multicolumn{6}{|c|}{ MIC $(\mu \mathrm{g} / \mathrm{mL})$ of Formulations } \\
\hline & \multirow[b]{2}{*}{ FLU } & \multicolumn{2}{|c|}{ MIC 50} & \multicolumn{3}{|c|}{ MIC 100} \\
\hline & & PHY & SLN-B & 10-SLN-PHY & 5-SLN-PHY & 3-SLN-PHY \\
\hline C. albicans ATCC 90028 & 0.125 & 2500 & $>173.5$ & 7.81 & 0.24 & 0.40 \\
\hline C. dubliniensis CBS 7987 & 0.5 & 2500 & $>173.5$ & 7.81 & 0.24 & 0.40 \\
\hline C. tropicalis ATCC 13803 & 0.5 & 1250 & $>173.5$ & 7.81 & 0.24 & 0.40 \\
\hline C. parapsilosis ATCC 22019 & 0.5 & 1250 & $>173.5$ & 3.90 & 0.24 & 0.40 \\
\hline C. glabrata ATCC 2001 & 0.5 & 625 & $>173.5$ & 1.95 & 0.24 & 0.40 \\
\hline C. rugosa ATCC 10571 & 0.125 & 1250 & $>173.5$ & 15.62 & 0.24 & 0.40 \\
\hline C. krusei ATCC 6258 & 16.0 & 2500 & $>173.5$ & 15.62 & 0.24 & 0.40 \\
\hline
\end{tabular}

Notes: FLU: fluconazole; ATCC: American Type Culture Collection; CBS: Centraalbureau voor Schimmelcultures; C.: Candida; MIC 50\%: minimum inhibitory concentration that inhibited 50\% growth; MIC $100 \%$ : minimum inhibitory concentration that inhibited any visible growth.

To achieve $100 \%$ of growth inhibition, we increased phytol concentration in the nanoparticle formulations. Subsequent tests were performed with the 5-SLN-PHY and 3-SLN-PHY and, as expected, the latest nanoparticles were able to induce a total visual growth inhibition of yeast cells at concentrations of 0.24 and $0.40 \mu \mathrm{g} / \mathrm{mL}$, respectively.

Among the strains tested, it is interesting to observe that the most remarkable result was found for the C. krusei ATCC 6258 strain, an intrinsically fluconazole-resistant Candida species (MIC of $16 \mu \mathrm{g} / \mathrm{mL}$ ) that showed very low MICs when grown in the presence of nanoparticles, with a concentration of $0.24 \mu \mathrm{g} / \mathrm{mL}$. Following a similar trend, low MICs were also found for C. tropicalis ATCC 13803, C. parapsilosis ATCC 22019, and C. glabrata ATCC 2001 strains, where the MIC for 5-SLN-PHY $(0.24 \mu \mathrm{g} / \mathrm{mL})$ was lower than the one found when cells where grown in the presence of fluconazole 
$(0.5 \mu \mathrm{g} / \mathrm{mL})$. Results regarding inhibition of the other reference strains were also satisfactory, considering that MIC of nanoparticles is at least like what was found for fluconazole.

In order to verify if the visual inhibition of $100 \%$ of yeast cells growth was due to a fungicidal action of the nanoparticles, we streaked out aliquots of each well on the surface of SDA in order to verify the absence or presence of fungal growth. As there was yeast growth on SDA, except for the negative control (as expected), the nanoparticles may have had a rather fungistatic action on Candida spp. cells.

\subsubsection{Fungal Minimal Inhibitory Concentration (MIC) in Candida spp. Clinical Isolates}

Under the same experimental conditions, PHY and SLN were tested against eight Candida spp. strains isolated from patients with vulvovaginal candidiasis and candidemia. The results are presented in Table 3. Again, the SLN-B was not able to inhibit yeast growth. However, contrary to the results found for the reference strains, the concentrations of PHY and 10-SLN-PHY tested were also not able to inhibit yeast growth of clinical isolates.

Table 3. Minimum inhibitory concentration values of phytol and SLN against Candida spp. clinical isolate strains determined with the broth microdilution assay.

\begin{tabular}{ccccccc}
\hline $\begin{array}{c}\text { Candida spp. } \\
\text { Clinical Isolates }\end{array}$ & \multicolumn{5}{c}{ MIC $(\mu \mathrm{g} / \mathbf{m L})$ of Formulations } \\
MIC 50 & \multicolumn{2}{c}{ MIC 100 } \\
\hline C. albicans LMMM 92 & 0.5 & $>10,000$ & $>173.5$ & $>62.5$ & $>125$ & $>208.3$ \\
C. albicans LMMM 100 & 0.5 & $>10,000$ & $>173.5$ & $>62.5$ & 0.24 & 0.40 \\
C. tropicalis LMMM 195 & 1.0 & $>10,000$ & $>173.5$ & $>62.5$ & 0.24 & 0.40 \\
C. tropicalis LMMM 447 & 2.0 & $>10,000$ & $>173.5$ & $>62.5$ & 0.24 & 0.40 \\
C. parapsilosis LMMM 83 & 0.125 & $>10,000$ & $>173.5$ & $>62.5$ & 0.24 & 0.40 \\
C. parapsilosis LMMM 85 & 16.0 & $>10,000$ & $>173.5$ & $>62.5$ & 0.24 & 0.40 \\
C. glabrata LMMM 704 & 2.0 & $>10,000$ & $>173.5$ & $>62.5$ & 0.24 & 0.40 \\
C. krusei LMMM 249 & 16.0 & $>10,000$ & $>173.5$ & $>62.5$ & 0.24 & 0.40 \\
\hline
\end{tabular}

Notes: FLU: fluconazole; LMMM: microbiology and medical mycology laboratory; C.: Candida; MIC 50\%: minimum inhibitory concentration that inhibited 50\% growth; MIC 100\%: minimum inhibitory concentration that inhibited any visible growth.

Interesting results were achieved after treatment with 5-SLN-PHY and 3-SLN-PHY as seven out of eight strains tested had a $100 \%$ MIC equivalent to $0.24 \mu \mathrm{g} / \mathrm{mL}$ and $0.40 \mu \mathrm{g} / \mathrm{mL}$, respectively. It is important to mention that the MICs obtained with the use of these nanoparticles were lower than the ones found when fluconazole was used (except for the $C$. albicans LMMM 92 strain).

The MICs for $100 \%$ visual inhibition after treatment with 5-SLN-PHY were also considered an incredible achievement, mainly considering the results with fluconazole. The achieved concentration of $0.24 \mu \mathrm{g} / \mathrm{mL}$ for C. parapsilosis LMMM 83, C. parapsilosis LMMM 85, C. glabrata LMMM 704, and C. krusei LMMM 249 was lower that determined when the fluconazolewas used. Conversely, C. albicans LMMM 100 showed higher MIC $(7.81 \mu \mathrm{g} / \mathrm{mL})$, while C. tropicalis LMMM 195 and LMMM 447 growth was not inhibited, even at the highest concentration.

Fluconazole was used as a control antifungal drug that is commercially available and has previously known anticandidal activity. It is known that this drug is fungistatic and acts by inhibiting the biosynthesis pathway of ergosterol by impairing the activity of the enzyme lanosterol $14-\alpha$-sterol demethylase [52]. The results showed that the use of nanoparticles was able to produce a total visual growth inhibition at lower concentrations than fluconazole, for both reference and clinical isolates (Tables 2 and 3). In fact, we must consider that the drug incorporated within SLN has advantages when compared to their unincorporated counterparts, such as a greater penetration into fungal cells, favored by the small size presented by the delivery system $[50,53]$. The same reason may justify the fact that 10-SLN-PHY has a MIC of 50\% inhibition activity approximately 300 times lower when compared to the PHY in the assays containing Candida spp. reference strains. It was also shown that when the phytol concentration incorporated in the nanoparticles was increased from 10-SLN-PHY to 5-SLN-PHY 
or 3-SLN-PHY, this inhibition reached $100 \%$. Other reported studies described nanotechnology approaches as strategy to obtain better results regarding antifungal activity [54-56].

Results from SLN tests with the Candida spp. reference strains showed that these nanoparticles were able to induce $100 \%$ growth inhibition. Here, two important aspects should be considered: the composition of the nanoparticles and their surface charge. The TG1, a constituent of the lipid matrix, is a triacyl glyceride of natural origin isolated from the plant Platonia insignis Mart [51]. There are few reports in the literature regarding its pharmacological properties. In addition to the cicatrizing activity cited below, the in vivo toxicity of this compound was also evaluated [57], and to date there are no reports of antifungal activity. Thus, we believe that through a synergistic activity between PHY and TG1 we are able to induce antifungal activity for the compound of natural origin [53].

For tests with clinical isolates, we showed that the tested concentrations of PHY, SLN-B, and 10-SLN-PHY were not effective in inducing growth inhibition. This finding may be related to possible antifungal selective pressure, with previous fungal cells exposure during patients' treatment. Eventually, horizontal transmission of resistant strains may occur among hospitalized patients, making the issue of resistance to conventional antifungal treatments a very serious problem [58]. Nevertheless, the visual growth inhibition of the clinical isolates after treatment with the other nanoparticles was similar to what was observed for the reference strains. Among the formulations tested, the one with the best biological activity was 5-SLN-PHY, because it was able to inhibit seven out of eight clinical strains in non-cytotoxic concentrations $(0.24 \mu \mathrm{g} / \mathrm{mL}$ of phytol; Table 3$)$.

In this study, we were able to show that phytol was effective against several medically important Candida species. Among them, C. albicans is considered the most virulent and frequently isolated Candida spp. from different anatomical sources [59]. C. albicans has the high ability to adhere to human epithelial cells; produces several enzymes such as hemolysins, phospholipases, and proteinases; and is a strong biofilm producer [60,61].

In addition, $C$. glabrata was generally the most susceptible species to the phytol activity. This is the second most frequently isolated species from patients with candidemia in North America and Europe [60]. This species shows pathogenic potential due to its ability to lyse erythrocytes and produce phospholipases [61]. Although it is a haploid and asexual yeast, the various selective pressures routinely suffered eventually favor its genetic diversity and evolution, causing alterations in genes that regulate the expression of virulence factors, possibly helping greater host adaptations [62]. Miranda-Cadena et al. (2018) reported the isolation of $C$. glabrata strains that showed a simultaneous cross-resistance profile to different azoles (fluconazole, itraconazole, and miconazole) [63].

The biological activity found in the present study for C. parapsilosis, C. tropicalis, and C. krusei are also relevant since these non-C. albicans Candida species are emerging in cases of invasive candidiasis. In Brazil, C. albicans, C. tropicalis, C. parapsilosis, and C. glabrata are recognized as the main etiological agents of bloodstream infections [64]. Specifically referring to C. parapsilosis, it can be said that it is considered an emerging species related to invasive candidiasis [64], as well as VVC [65]. Hashemi et al. (2019) investigated species distribution and antifungal susceptibility of Candida spp. isolated from patients diagnosed with VVC and found that $C$. parapsilosis was the third most prevalent species, while C. albicans was the first [66].

In the literature, we have not found data on the precise mechanism of phytol's antifungal activity, but as it is a component present in essential oils, we can suggest that it is causing yeast death due to a de-stabilization in the fungal cell membrane [67]. As a way of reinforcing this hypothesis, in the study developed by Bakkali and co-workers (2008), the authors postulated phytol-containing essential oils to destabilize eukaryotic cells, increasing cell membrane permeability, as well as promoting mitochondrial membrane depolarization [68]. In addition, Barros de Alencar and co-workers (2017) extensively reviewed the action of diterpenes against neglected diseases and reported that substances with one or more -OH active groups that also have antioxidant activity can increase membrane permeability of a variety of organisms such as bacteria, fungi, and viruses [69]. 


\subsection{In Vitro Viability Assay}

Considering the anticandidal assays, we performed cell viability assays for the two best formulations, the 5-SLN-PHY and 3-SLN-PHY samples. This experiment was performed for evaluating in vitro biocompatibility of free-drug SLN and understanding how the phytol changed this property. In addition, the cytotoxic effect of phytol was previously reported in the literature [24,25], and the possible enhancement of this biological effect reinforced the ability of the nanocarrier to improve the phytol interaction with cells.

The results of the cell viability assay are shown in Figure 4. After analyses, the results indicated that PHY at concentrations ranging from 250 to $3.9 \mu \mathrm{g} / \mathrm{mL}$ was well tolerated by HEK-293 cells, demonstrating a low cytotoxic effect over time and indicating cytotoxic concentration to $50 \%$ of the cells $\left(\mathrm{CC}_{50}\right)$ was $>250 \mu \mathrm{g} / \mathrm{mL}$ (Figure $4 \mathrm{a}$ ). In the first $24 \mathrm{~h}$, at all concentrations tested, cell viability was estimated to be equal to or greater than $90 \%$. In results for $48 \mathrm{~h}$, cell viability decreased, and a dose-dependent profile was identified. Concentrations equal to or lower than $62.5 \mu \mathrm{g} / \mathrm{mL}$ were considered biocompatible for the cells that presented more than $80 \%$ of cellular viability. In addition, the SLN-B was also well tolerated at the tested concentrations, even after $48 \mathrm{~h}$ of incubation (Figure $4 \mathrm{~b}$ ).

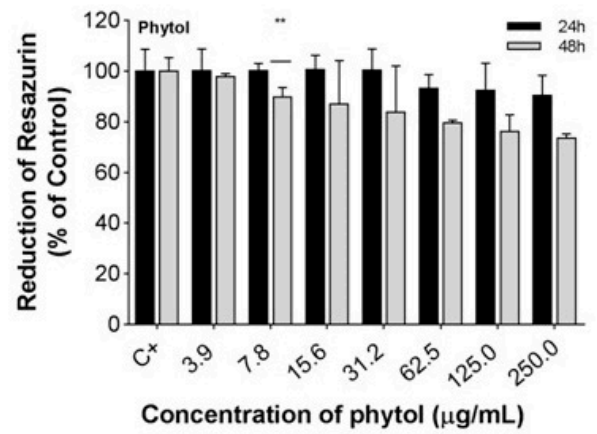

(a)

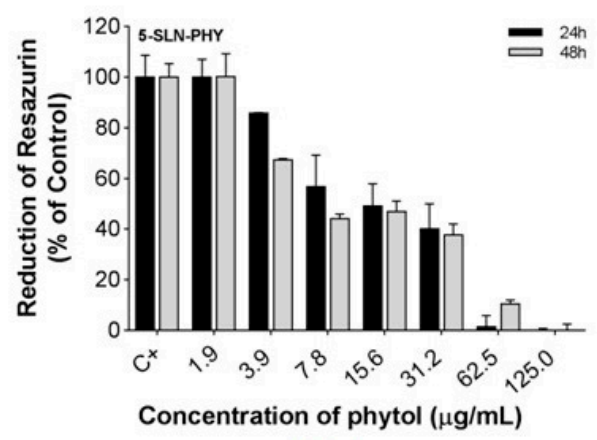

(c)

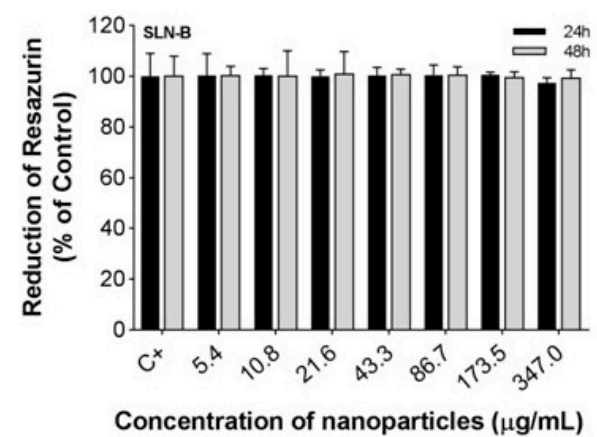

(b)

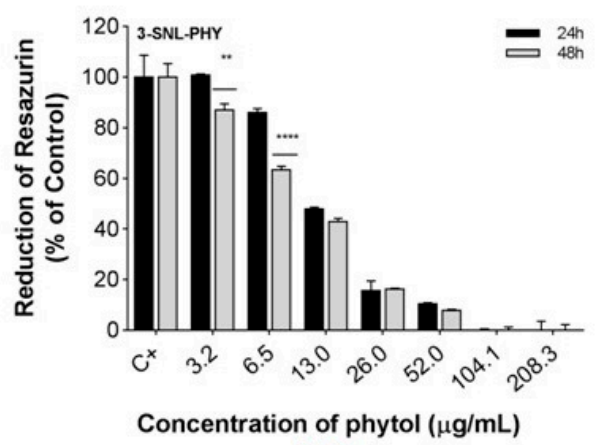

(d)

Figure 4. Cell viability in HEK-293. Assay performed after the cells incubation with (a) phytol; (b) blank-solid lipid nanoparticles (SLN-B); (c) phytol-loaded in solid lipid nanoparticles 1:5 (5-SLN-PHY); (d) phytol-loaded in solid lipid nanoparticles 1:3 (3-SLN-PHY). All measurements were carried out in triplicate with three replicates for each dilution. The cell viability was defined in comparison to untreated controls. The statistical was performed using the two-way ANOVA of distinct concentrations tested at $24 \mathrm{~h}$ vs $48 \mathrm{~h}$. A $p<0.01$ was represented as ** and $p<0.001$ as ****.

Tests with 5-SLN-PHY showed the occurrence of a dose-dependent cytotoxic effect and the fact that within the first $24 \mathrm{~h}$ of incubation, the highest tested concentration $(125 \mu \mathrm{g} / \mathrm{mL})$ was toxic to cells (Figure 4c). This effect was enhanced when the drug loading was augmented in 3-SLN-PHY (Figure 4d). This fact can be better observed in Table 4 . The estimated $\mathrm{CC}_{50}$ of 13.34 and $10.5 \mu \mathrm{g} / \mathrm{mL}$ were observed for 5-SLN-PHY and 3-SLN-PHY, respectively. 
Table 4. $\mathrm{CC}_{50}$ values for different samples.

\begin{tabular}{cc}
\hline Formulations & (CC50 $\boldsymbol{\mu g} / \mathbf{m L})$ \\
\hline PHY & $>250$ \\
SLN-B & $>347$ \\
5-SLN-PHY & 13.34 \\
3-SLN-PHY & 10.50 \\
\hline
\end{tabular}

Notes: Data are expressed as mean \pm standard deviation (SD) from three independent experiments, with each treatment performed in triplicate; $\mathrm{CC}_{50}$ : concentration that was cytotoxic for $50 \%$ of the cells.

These achievements proved the expected ability of SLN for improving the drug uptake. Solid lipid nanoparticles are drug delivery systems that are capable of improving the bioavailability of poorly soluble molecules in aqueous environments, as well as promoting protection, high stability, and controlled release of the compound that is dissolved or dispersed in the lipid matrix [50]. Regarding cytotoxicity, we can say that it is very important to perform in vitro viability assays carried out in the initial stages of a study, since they allow access to preliminary data regarding a possible cytotoxicity of the new compound being tested [70].

As shown in Figure 4c,d, PHY-loaded SLNs caused a dose-dependent cytotoxic effect as a function of time at the highest concentrations tested. Islam and co-workers (2017) evaluated the cytotoxic potential of phytol in Artemia salina and suggested that the cytotoxicity of this compound is due to a succession of events, among them, failure of ATP supply, changes in membrane potential, probable increase in the formation of reactive oxygen species (ROS), and changes in $\mathrm{Na}^{+} / \mathrm{K}^{+}$pump functioning, resulting in a greater influx of $\mathrm{Na}^{+}$and $\mathrm{Ca}^{2+}$ as well as changes in membrane-selective permeability, which leads to cell death [32].

SLN-B was not cytotoxic to HEK-239 cells at the concentrations tested, suggesting that the system is biocompatible. Indeed, Mendes and co-works (2015) evaluated the healing potential of TG1 in vivo and found that pharmaceutical formulations containing up to $7.5 \mathrm{~g}$ of TG1 were not considered toxic and were effective in the process of reestablishing the integrity of the animals' skin [57]. The experimental data discussed in this study corroborates the potential and promising nature of TG1-based SLN as a biocompatible and efficient nanocarrier for phytol. In addition, the ability of nanoparticles to facilitate the drug transport through the biological membranes is well explored [71]. An increased uptake of phytol supposedly increases its inhibitory effect, a relevant property mainly considering its antimicrobial use.

As previously mentioned, there are no reports in the literature regarding the elucidation of the mechanism of action of either free or incorporated phytol against Candida spp. However, it is known that molecules with antifungal activity when in contact with fungal cells first interact with the constituents of the cell wall, mainly the polysaccharides, and then with cell membrane composed of phospholipids and ergosterol. Finally, there is interactions with the other internal structures such as organelles [72,73]. Nevertheless, we currently did not aim to investigate the molecular interaction and mechanism of action of the nanoparticles with Candida cells. However, given their size, we assume that phytol nanoparticles are able to cross the fungal cell wall and interact with plasma membrane and other internal organelles, possibly interfering with structure organization and metabolic pathways that are important for fungal cell fitness, leading to $\mathrm{K}^{+}$leakage [33,34]. Further analysis is needed to investigate the mechanism of action.

\section{Conclusions}

The results presented in this study explored the phytol as a bioactive compound that is able to be used and an innovative anticandidal compound incorporated in solid lipid nanoparticles. We realize that it is possible to modulate the anticandidal effect of formulations by hanging phytol/TG1 ratio. The experimental design was efficient to prove this purpose. The prepared formulations exhibited interesting properties such uniform particle size distribution, phytol content, and physical stability. 
The biocompatibility of free-drug SLN was assessed in HEK-3 cells. The experimental achievements demonstrated the potential of this nanocarrier, which was prepared using a naturally occurring lipid matrix and low surfactant concentrations. As we hypothesized, the drug-loaded SLN presented a dose-dependent anticandidal effect, and was able to inhibit the fungal proliferation of reference strains, as well as clinical isolates obtained from patients with vulvovaginal candidiasis or candidemia. These achievements can be considered excellent, mainly considering the superior performance of SLN formulations compared to fluconazole drug. The experimental data discussed in this study certainly support further experiments to stabilize these formulations as powder and in vivo studies in specific candidemia models of this promising nanobiotechnological approach for anticandidal therapy.

\section{Patients}

The clinical isolates used in this study were collected from patients with vulvovaginal candidiasis (LMMM 92 and LMMM 100) or candidemia (LMMM 83, LMMM 85, LMMM 195, LMMM 249, LMMM 447, LMMM 704). These belong to the culture collection of the Medical and Molecular Mycology Laboratory, Clinical and Toxicological Analyses Department at the Federal University of Rio Grande do Norte. This study was approved by the Local Research Ethics Committee ("Comitê de Ética em Pesquisa da Liga Norte Riograndense Contra o Câncer") under the protocol number 042/042/2012.

Author Contributions: T.L.C.L., L.B.F.C.S.: investigation, methodology, formal analysis, and writing-original draft; A.M.d.S.-S., L.C.S.T.-P., R.S.C., R.F.d.A.-J.: methodology; M.F.F.-P., A.M.C.: visualization, writing-original draft; G.M.C., A.A.d.S.-J.: conceptualization, formal analysis, writing-review and editing, supervision, project administration, funding acquisition. All authors have read and agreed to the published version of the manuscript.

Funding: This research was funded by the Brazilian National Council for Scientific and Technological Development (CNPq) for financial support [436051/2018-4; 308382/2017-0] and "Coordenação de aperfeiçoamento de Pessoal de Nível Superior (CAPES) [finance code: 001].

Acknowledgments: In memoriam to the great pharmacist and researcher, Rivelilson Mendes de Freitas, from the Federal University of Piauí for supplying the TG1 lipid.

Conflicts of Interest: The authors declare no conflict of interest.

\section{References}

1. Bongomin, F.; Gago, S.; Oladele, R.O.; Denning, D.W. Global and Multi-National Prevalence of Fungal Diseases-Estimate Precision. J. Fungi 2017, 3, 57. [CrossRef]

2. Metin, A.; Dilek, N.; Bilgili, S.G. Recurrent candidal intertrigo: Challenges and solutions. Clin. Cosmet. Investig. Dermatol. 2018, 11, 175-185. [CrossRef]

3. Sawant, B.; Khan, T. Recent advances in delivery of antifungal agents for therapeutic management of candidiasis. Biomed. Pharmacother. 2017, 96, 1478-1490. [CrossRef]

4. Naglik, J.R.; König, A.; Hube, B.; Gaffen, S.L. Candida albicans-epithelial interactions and induction of mucosal innate immunity. Curr. Opin. Microbiol. 2017, 40, 104-112. [CrossRef]

5. Schlecht, L.M.; Peters, B.M.; Krom, B.P.; Freiberg, J.A.; Hänsch, G.M.; Filler, S.G.; Jabra-Rizk, M.A.; Shirtliff, M.E. Systemic Staphylococcus aureus infection mediated by Candida albicans hyphal invasion of mucosal tissue. Microbiology 2015, 161, 168-181. [CrossRef]

6. Pappas, P.G.; Kauffman, C.A.; Andes, D.R.; Clancy, C.J.; Marr, K.A.; Ostrosky-Zeichner, L.; Reboli, A.C.; Schuster, M.G.; Vazquez, J.A.; Walsh, T.J.; et al. Clinical Practice Guideline for the Management of Candidiasis: 2016 Update by the Infectious Diseases Society of America. Clin. Infect. Dis. 2015, 62, civ933. [CrossRef]

7. De Medeiros, M.A.P.; Vieira De Melo, P.; Gonçalves, S.S.; Milan, E.P.; Chaves, G.M. Genetic relatedness among vaginal and anal isolates of Candida albicans from women with vulvovaginal candidiasis in North-East Brazil. J. Med. Microbiol. 2014, 63, 1436-1445. [CrossRef]

8. Pappas, P.G.; Kauffman, C.A.; Andes, D.; Benjamin, D.K., Jr.; Calandra, T.F.; Edwards, J.E., Jr.; Filler, S.G.; Fisher, J.F.; Kullberg, B.; Ostrosky-Zeichner, L.; et al. Clinical Practice Guidelines for the Management of Candidiasis: 2009 Update by the Infectious Diseases Society of America. Clin. Infect. Dis. 2009, 48, 503-535. [CrossRef] 
9. Kullberg, B.J.; Arendrup, M.C. Invasive Candidiasis. N. Engl. J. Med. 2015, 373, 1445-1456. [CrossRef]

10. Vallabhaneni, S.; Mody, R.K.; Walker, T.; Chiller, T. The Global Burden of Fungal Diseases. Infect. Dis. Clin. N. Am. 2016, 30, 1-11. [CrossRef]

11. McCarty, T.P.; Pappas, P.G. Invasive Candidiasis. Infect. Dis. Clin. N. Am. 2016, 30, 103-124. [CrossRef]

12. de Cássia Orlandi Sardi, J.; Silva, D.R.; Soares Mendes-Giannini, M.J.; Rosalen, P.L. Candida auris: Epidemiology, risk factors, virulence, resistance, and therapeutic options. Microb. Pathog. 2018, 125, 116-121. [CrossRef]

13. Pristov, K.E.; Ghannoum, M.A. Resistance of Candida to azoles and echinocandins worldwide. Clin. Microbiol. Infect. 2019, 25, 792-798. [CrossRef]

14. Souza, M.E.; Lopes, L.Q.S.; Bonez, P.C.; Gündel, A.; Martinez, D.S.T.; Sagrillo, M.R.; Giongo, J.L.; Vaucher, R.A.; Raffin, R.P.; Boligon, A.A.; et al. Melaleuca alternifolia nanoparticles against Candida species biofilms. Microb. Pathog. 2017, 104, 125-132. [CrossRef]

15. Siqueira, A.B.S.; Rodriguez, L.R.N.D.A.; SANTOS, R.K.B.; Marinho, R.R.B.; Abreu, S.; Peixoto, R.F.; Gurgel, B.C.D.V. Antifungal activity of propolis against Candida species isolated from cases of chronic periodontitis. Braz. Oral Res. 2015, 29, 1-6. [CrossRef]

16. de Moraes, J.; de Oliveira, R.N.; Costa, J.P.; Junior, A.L.G.; de Sousa, D.P.; Freitas, R.M.; Allegretti, S.M.; Pinto, P.L.S. Phytol, a Diterpene Alcohol from Chlorophyll, as a Drug against Neglected Tropical Disease Schistosomiasis Mansoni. PLoS Negl. Trop. Dis. 2014, 8, e2617. [CrossRef]

17. Baldim, I.; Tonani, L.; von Zeska Kress, M.R.; Pereira Oliveira, W. Lippia sidoides essential oil encapsulated in lipid nanosystem as an anti-Candida agent. Ind. Crops Prod. 2019, 127, 73-81. [CrossRef]

18. Islam, M.T.; da Mata, A.M.O.F.; de Aguiar, R.P.S.; Paz, M.F.C.J.; de Alencar, M.V.O.B.; Ferreira, P.M.P.; de Carvalho Melo-Cavalcante, A.A. Therapeutic Potential of Essential Oils Focusing on Diterpenes. Phyther. Res. 2016, 30, 1420-1444. [CrossRef]

19. Islam, M.T.; de Alencar, M.V.O.B.; da Conceição Machado, K.; da Conceição Machado, K.; de Carvalho Melo-Cavalcante, A.A.; de Sousa, D.P.; de Freitas, R.M. Phytol in a pharma-medico-stance. Chem. Biol. Interact. 2015, 240, 60-73. [CrossRef]

20. Islam, M.T. Diterpenes and Their Derivatives as Potential Anticancer Agents. Phyther. Res. 2017, 31, 691-712. [CrossRef]

21. Islam, M.T.; Ali, E.S.; Uddin, S.J.; Shaw, S.; Islam, M.A.; Ahmed, M.I.; Chandra Shill, M.; Karmakar, U.K.; Yarla, N.S.; Khan, I.N.; et al. Phytol: A review of biomedical activities. Food Chem. Toxicol. 2018, 121, 82-94. [CrossRef]

22. Ghaneian, M.T.; Ehrampoush, M.H.; Jebali, A.; Hekmatimoghaddam, S.; Mahmoudi, M. Antimicrobial activity, toxicity and stability of phytol as a novel surface disinfectant. Environ. Heal. Eng. Manag. J. 2015, 2, $13-16$.

23. Costa, J.P.; Islam, M.T.; Santos, P.S.; Ferreira, P.B.; Oliveira, G.L.S.; Alencar, M.V.O.B.; Paz, M.F.C.J.; Ferreira, É.L.F.; Feitosa, C.M.; Citó, A.M.G.L.; et al. Evaluation of Antioxidant Activity of Phytol Using Nonand Pre-Clinical Models. Curr. Pharm. Biotechnol. 2016, 17, 1278-1284. [CrossRef]

24. Islam, M.T.; Streck, L.; Correia Jardim Paz, M.F.; de Castro e Sousa, J.M.; Oliveira Barros de Alencar, M.V.; Oliveira Ferreira da Mata, A.M.; Melo de Carvalho, R.; de Oliveira Santos, J.V.; da Silva-Junior, A.A.; Pinheiro Ferreira, P.M.; et al. Preparation of phytol-loaded nanoemulsion and screening for antioxidant capacity. Int. Arch. Med. 2016, 1-15. [CrossRef]

25. Sakthivel, R.; Malar, D.S.; Devi, K.P. Phytol shows anti-angiogenic activity and induces apoptosis in A549 cells by depolarizing the mitochondrial membrane potential. Biomed. Pharmacother. 2018, 105, 742-752. [CrossRef]

26. Pejin, B.; Savic, A.; Sokovic, M.; Glamoclija, J.; Ciric, A.; Nikolic, M.; Radotic, K.; Mojovic, M. Further in vitro evaluation of antiradical and antimicrobial activities of phytol. Nat. Prod. Res. 2014, 28, 372-376. [CrossRef]

27. McGinty, D.; Letizia, C.S.; Api, A.M. Fragrance material review on phytol. Food Chem. Toxicol. 2010, 48, S59-S63. [CrossRef]

28. Nakhlband, A.; Eskandani, M.; Saeedi, N.; Ghafari, S.; Omidi, Y.; Barar, J.; Garjani, A. Marrubiin-loaded solid lipid nanoparticles' impact on TNF- $\alpha$ treated umbilical vein endothelial cells: A study for cardioprotective effect. Colloids Surf. B Biointerfaces 2018, 164, 299-307. [CrossRef] 
29. Sathya, S.; Shanmuganathan, B.; Saranya, S.; Vaidevi, S.; Ruckmani, K.; Pandima Devi, K. Phytol-loaded PLGA nanoparticle as a modulator of Alzheimer's toxic A $\beta$ peptide aggregation and fibrillation associated with impaired neuronal cell function. Artif. Cells Nanomedicine Biotechnol. 2017, 46, 1719-1730. [CrossRef]

30. Sathya, S.; Shanmuganathan, B.; Balasubramaniam, B.; Balamurugan, K.; Devi, K.P. Phytol loaded PLGA nanoparticles regulate the expression of Alzheimer's related genes and neuronal apoptosis against amyloid- $\beta$ induced toxicity in Neuro-2a cells and transgenic Caenorhabditis elegans. Food Chem. Toxicol. 2020, 136, 110962. [CrossRef]

31. Sathya, S.; Manogari, B.G.; Thamaraiselvi, K.; Vaidevi, S.; Ruckmani, K.; Devi, K.P. Phytol loaded PLGA nanoparticles ameliorate scopolamine-induced cognitive dysfunction by attenuating cholinesterase activity, oxidative stress and apoptosis in Wistar rat. Nutr. Neurosci. 2020,1-17. [CrossRef] [PubMed]

32. Islam, M.T.; Streck, L.; de Alencar, M.V.O.B.; Cardoso Silva, S.W.; da Conceição Machado, K.; da Conceição Machado, K.; Gomes Júnior, A.L.; Paz, M.F.C.J.; da Mata, A.M.O.F.; de Castro e Sousa, J.M.; et al. Evaluation of toxic, cytotoxic and genotoxic effects of phytol and its nanoemulsion. Chemosphere 2017, 177, 93-101. [CrossRef] [PubMed]

33. Omoruyi, B.E.; Afolayan, A.J.; Bradley, G. Chemical composition profiling and antifungal activity of the essential oil and plant extracts of Mesembryanthemum edule (L.) bolus leaves. Afr. J. Tradit. Complement Altern. Med. 2014, 11, 19-30. [CrossRef]

34. Khameneh, B.; Iranshahy, M.; Soheili, V.; Bazzaz, B.S.F. Review on plant antimicrobials: A mechanistic viewpoint. Antimicrob. Resist. Infect. Control. 2019, 8, 118. [CrossRef] [PubMed]

35. Sahay, G.; Alakhova, D.Y.; Kabanov, A.V. Endocytosis of nanomedicines. J. Control. Release 2010, 145, $182-195$. [CrossRef] [PubMed]

36. Kakadia, P.G.; Conway, B.R. Solid Lipid Nanoparticles: A Potential Approach for Dermal Drug Delivery. Am. J. Pharmacol. Sci. 2014, 2,1-7. [CrossRef]

37. Danaei, M.; Dehghankhold, M.; Ataei, S.; Hasanzadeh Davarani, F.; Javanmard, R.; Dokhani, A.; Khorasani, S.; Mozafari, M.R. Impact of particle size and polydispersity index on the clinical applications of lipidic nanocarrier systems. Pharmaceutics 2018, 10, 57. [CrossRef]

38. CLSI. Reference Method for Broth Dilution; Clinical and Laboratory Standards Institute: Wayne, PA, USA, 2008; Volume 3.

39. Souza, L.; Silva-Rocha, W.; Ferreira, M.; Soares, L.; Svidzinski, T.; Milan, E.; Pires, R.; Fusco Almeida, A.; Mendes-Giannini, M.; Maranhão Chaves, G. Influence of Eugenia uniflora Extract on Adhesion to Human Buccal Epithelial Cells, Biofilm Formation, and Cell Surface Hydrophobicity of Candida spp. from the Oral Cavity of Kidney Transplant Recipients. Molecules 2018, 23, 2418. [CrossRef]

40. Lima, T.; Feitosa, R.; dos Santos-Silva, E.; dos Santos-Silva, A.; Siqueira, E.; Machado, P.; Cornélio, A.; do Egito, E.; Fernandes-Pedrosa, M.; Farias, K.; et al. Improving Encapsulation of Hydrophilic Chloroquine Diphosphate into Biodegradable Nanoparticles: A Promising Approach against Herpes Virus Simplex-1 Infection. Pharmaceutics 2018, 10, 255. [CrossRef]

41. dos Santos-Silva, A.M.; de Caland, L.B.; de SL Oliveira, A.L.C.; de Araújo-Júnior, R.F.; Fernandes-Pedrosa, M.F.; Cornélio, A.M.; da Silva-Júnior, A.A. Designing structural features of novel benznidazole-loaded cationic nanoparticles for inducing slow drug release and improvement of biological efficacy. Mater. Sci. Eng. C 2017, 78, 978-987. [CrossRef]

42. Pooja, D.; Tunki, L.; Kulhari, H.; Reddy, B.B.; Sistla, R. Optimization of solid lipid nanoparticles prepared by a single emulsification-solvent evaporation method. Data Br. 2016, 6, 15-19. [CrossRef] [PubMed]

43. Behzadi, S.; Serpooshan, V.; Wei, T.; Hamaly, M.A.; Alkawareek, M.Y.; Dreaden, E.C.; Brown, D.; Alkilany, A.M.; Farokhzad, O.C.; Mahmoudi, M. Cellular Uptake of Nanoparticles: Journey Inside the Cell. Chem. Soc. Rev. 2017, 46, 4218-4244. [CrossRef] [PubMed]

44. Blanco, E.; Shen, H.; Ferrari, M. Principles of nanoparticle design for overcoming biological barriers to drug delivery. Nat. Biotechnol. 2015, 33, 941-951. [CrossRef] [PubMed]

45. Hamishehkar, H.; Bahadori, M.B.; Vandghanooni, S.; Eskandani, M.; Nakhlband, A.; Eskandani, M. Preparation, characterization and anti-proliferative effects of sclareol-loaded solid lipid nanoparticles on A549 human lung epithelial cancer cells. J. Drug Deliv. Sci. Technol. 2018, 45, 272-280. [CrossRef]

46. Zhang, D.; Dai, W.; Duan, C.; Jia, L.; Wang, Y.; Feng, F.; Zhang, Q. Preparation and characteristics of oridonin-loaded nanostructured lipid carriers as a controlled-release delivery system. J. Microencapsul. 2010, 27, 234-241. [CrossRef] 
47. Gordillo-Galeano, A.; Mora-Huertas, C.E. Solid lipid nanoparticles and nanostructured lipid carriers: A review emphasizing on particle structure and drug release. Eur. J. Pharm. Biopharm. 2018, 133, 285-308. [CrossRef]

48. Dendisová, M.; Jeništová, A.; Parchaňská-kokaislová, A.; Matějka, P.; Prokopec, V.; Švecová, M. The use of infrared spectroscopic techniques to characterize nanomaterials and nanostructures: A review. Anal. Chim. Acta 2018, 1031, 1-14. [CrossRef]

49. Matos, S.; Carvalho, D.; Montanheiro, C.; Gonçalves, C.; Gustavo, W.; Casagrande, I.; Ramos, M.; Cleber, F.; Luiz, P.; Barreto, M. PVA antioxidant nanocomposite films functionalized with alpha-tocopherol loaded solid lipid nanoparticles. Colloids Surf. A 2019, 581, 123793. [CrossRef]

50. Mishra, V.; Bansal, K.K.; Verma, A.; Yadav, N.; Thakur, S.; Sudhakar, K.; Rosenholm, J.M. Solid lipid nanoparticles: Emerging colloidal nano drug delivery systems. Pharmaceutics 2018, 10, 191. [CrossRef]

51. Feitosa, C.M.; dos Santos, P.R.P.; de Freitas, R.M.; Rodrigues, A.M.X.; de Oliveira, G.A.L.; da Costa Junior, J.S.; Cavalcante, A.D.N. Pre clinical trials in rats treated with 1,3-distearoyl-2-oleoylglycerol (TG1) constituent isolated from Platonia insignis. ConScientiae Saúde 2015, 14, 555-567. [CrossRef]

52. Berkow, E.L.; Lockhart, S.R. Fluconazole resistance in Candida species: A current perspective. Infect. Drug Resist. 2017, 10, 237-245. [CrossRef] [PubMed]

53. Gómez-Sequeda, N.; Torres, R.; Ortiz, C. Synthesis, characterization, and in vitro activity against Candida spp. Of fluconazole encapsulated on cationic and conventional nanoparticles of poly(lactic-co-glycolic acid). Nanotechnol. Sci. Appl. 2017, 10, 95-104. [CrossRef] [PubMed]

54. Domingues Bianchin, M.; Borowicz, S.M.; da Rosa Monte Machado, G.; Pippi, B.; Stanisçuaski Guterres, S.; Raffin Pohlmann, A.; Meneghello Fuentefria, A.; Clemes Külkamp-Guerreiro, I. Lipid core nanoparticles as a broad strategy to reverse fluconazole resistance in multiple Candida species. Colloids Surf. B Biointerfaces 2019, 175, 523-529. [CrossRef] [PubMed]

55. Moazeni, M.; Kelidari, H.R.; Saeedi, M.; Morteza-Semnani, K.; Nabili, M.; Abdollahi Gohar, A.; Akbari, J.; Lotfali, E.; Nokhodchi, A. Time to overcome fluconazole resistant Candida isolates: Solid lipid nanoparticles as a novel antifungal drug delivery system. Colloids Surf. B Biointerfaces 2016, 142, 400-407. [CrossRef] [PubMed]

56. Svetlichny, G.; Kulkamp-Guerreiro, I.C.; Cunha, S.L.; Silva, F.E.K.; Bueno, K.; Pohlmann, A.R.; Fuentefria, A.M.; Guterres, S.S. Solid lipid nanoparticles containing copaiba oil and allantoin: Development and role of nanoencapsulation on the antifungal activity. Die Pharm. Int. J. Pharm. Sci. 2015, 70, 155-164. [CrossRef]

57. Mendes, M.C.S.; de Oliveira, A.L.G.; Lacerda, J.S.; Rezende-Júnior, L.M.; da Silva, M.L.G.; Coêlho, M.L.; Tomé, A.R.; da Costa-Júnior, J.S.; Ferraz, A.B.F.; David, J.M.; et al. Evaluation of the cicatrizant activity of a semisolid pharmaceutical formulation obtained from Platonia insignis Mart. Afr. J. Pharm. Pharmacol. 2015, 9, 154-164. [CrossRef]

58. Arendrup, M.C.; Patterson, T.F. Multidrug-Resistant Candida: Epidemiology, Molecular Mechanisms, and Treatment. J. Infect. Dis. 2017, 216, S445-S451. [CrossRef]

59. Pfaller, M.A.; Diekema, D.J. Epidemiology of invasive candidiasis: A persistent public health problem. Clin. Microbiol. Rev. 2007, 20, 133-163. [CrossRef]

60. Diekema, D.; Arbefeville, S.; Boyken, L.; Kroeger, J.; Pfaller, M. The changing epidemiology of healthcare-associated candidemia over three decades. Diagn. Microbiol. Infect. Dis. 2012, 73, 45-48. [CrossRef]

61. Vieira de Melo, A.P.; Zuza-Alves, D.L.; da Silva-Rocha, W.P.; Ferreira Canário de Souza, L.B.; Francisco, E.C.; Salles de Azevedo Melo, A.; Maranhão Chaves, G. Virulence factors of Candida spp. obtained from blood cultures of patients with candidemia attended at tertiary hospitals in Northeast Brazil. J. Mycol. Med. 2019. [CrossRef]

62. Guo, X.; Zhang, R.; Li, Y.; Wang, Z.; Ishchuk, O.P.; Ahmad, K.M.; Wee, J.; Piskur, J.; Shapiro, J.A.; Gu, Z. Understand the genomic diversity and evolution of fungal pathogen Candida glabrata by genome-wide analysis of genetic variations. Methods 2019. [CrossRef] [PubMed]

63. Miranda-Cadena, K.; Marcos-Arias, C.; Mateo, E.; Aguirre, J.M.; Quindós, G.; Eraso, E. Prevalence and antifungal susceptibility profiles of Candida glabrata, Candida parapsilosis and their close-related species in oral candidiasis. Arch. Oral Biol. 2018, 95, 100-107. [CrossRef] [PubMed]

64. Medeiros, M.A.P.D.; Melo, A.P.V.D.; Bento, A.D.O.; Souza, L.B.F.C.D.; Neto, F.D.A.B.; Garcia, J.B.L.; Luzia-Alves, D.; Francisco, E.C.; Melo, A.S.D.A.D.; Chaves, G.M. Epidemiology and prognostic factors of nosocomial candidemia in Northeast Brazil: A six-year retrospective study. PLoS ONE 2019, 14, e0221033. [CrossRef] [PubMed] 
65. Zhu, Y.; Shan, Y.; Fan, S.; Li, J.; Liu, X. Candida parapsilosis Sensu Stricto and the Closely Related Species Candida orthopsilosis and Candida metapsilosis in Vulvovaginal Candidiasis. Mycopathologia 2015, 179, 111-118. [CrossRef]

66. Hashemi, S.E.; Shokohi, T.; Abastabar, M.; Aslani, N.; Ghadamzadeh, M.; Haghani, I. Species distribution and susceptibility profiles of Candida species isolated from vulvovaginal candidiasis, emergence of C. lusitaniae. Curr. Med Mycol. 2019, 5, 26-34. [CrossRef]

67. Ahmad, A.; Khan, A.; Kumar, P.; Bhatt, R.P.; Manzoor, N. Antifungal activity of Coriaria nepalensis essential oil by disrupting ergosterol biosynthesis and membrane integrity against Candida. Yeast 2011, 28, 611-617. [CrossRef]

68. Bakkali, F.; Averbeck, S.; Averbeck, D.; Idaomar, M. Biological effects of essential oils-A review. Food Chem. Toxicol. 2008, 46, 446-475. [CrossRef]

69. Barros de Alencar, M.V.O.; de Castro e Sousa, J.M.; Rolim, H.M.L.; de Medeiros, M.d.G.F.; Cerqueira, G.S.; de Castro Almeida, F.R.; Citó, A.M.d.G.L.; Ferreira, P.M.P.; Lopes, J.A.D.; de Carvalho Melo-Cavalcante, A.A.; et al. Diterpenes as lead molecules against neglected tropical diseases. Phyther. Res. 2017, 31, 175-201. [CrossRef]

70. K Mazu, T.; A Bricker, B.; Flores-Rozas, H.; Y Ablordeppey, S. The Mechanistic Targets of Antifungal Agents: An Overview. Mini-Rev. Med. Chem. 2016, 16, 555-578. [CrossRef]

71. Vasir, J.K.; Labhasetwar, V. Quantification of the force of nanoparticle-cell membrane interactions and its influence on intracellular trafficking of nanoparticles. Biomaterials 2008, 29, 4244-4252. [CrossRef]

72. Garcia-Rubio, R.; de Oliveira, H.C.; Rivera, J.; Trevijano-Contador, N. The Fungal Cell Wall: Candida, Cryptococcus, and Aspergillus Species. Front. Microbiol. 2020, 10, 1-13. [CrossRef] [PubMed]

73. Tada, R.; Latge, J.-P.; Aimanianda, V. Undressing the Fungal Cell Wall/Cell Membrane-the Antifungal Drug Targets. Curr. Pharm. Des. 2013, 19, 3738-3747. [CrossRef] [PubMed]

(C) 2020 by the authors. Licensee MDPI, Basel, Switzerland. This article is an open access article distributed under the terms and conditions of the Creative Commons Attribution (CC BY) license (http://creativecommons.org/licenses/by/4.0/). 